\title{
Quantile-VaR is the Wrong Measure to Quantify Market Risk for Regulatory Purposes*
}

\author{
Stefan R. Jaschke ${ }^{\mathrm{a}}$ \\ ${ }^{a}$ Weierstraß-Institut für Angewandte Analysis und Stochastik, Mohrenstraße 39, 10117 \\ Berlin, Germany, stefan@jaschke-net.de
}

Version 1.0, May 31, 2001

\begin{abstract}
Starting from the objective of banking supervision - to minimize the overall costs of banking to the general public - we show that the current standard of quantifying market risk is flawed. It is perfectly aligned with the interests of banks' shareholders and management, but not with the interests of the general public. This is unsatisfactory from a normative point of view, as significant public resources are used for banking supervision.
\end{abstract}

Keywords: banking regulation, supervision, VaR, risk measures, Basel Accord

JEL Classification: K2, G2

\section{The Objective of Banking Supervision}

The "New Basel Capital Accord" (Basel Committee on Banking Supervision; 2001) improves on the current regulation in many aspects, among them (1) the recognition of credit and operational risk, (2) more weight on processes and practices (pillar 2), and (3) better disclosure (pillar 3). Good risk management has many aspects. One of the more costly aspects is the implementation of interfaces to a plethora of front-office systems, back-office systems, and databases of market data. The costs associated with methodological and mathematical questions is dwarfed by the necessary investments in information technology (IT) infra-structure, by both banks and regulators. Another organizational and social challenge is to use the computed numbers to actually control risk, i.e. to build an atmosphere where individuals accept the risk management system and behave accordingly. An inappropriate risk measure or methodology, however, could jeopardize all the other costs and efforts put into supervision and risk management systems.

${ }^{*}$ Disclaimer. The views herein are solely those of the author, not the Weierstrass-Institute. As the wording is somewhat informal, this comment on the "New Basel Capital Accord" should not be considered a scientific work. 
Put differently, prudent practices to run a general business are numerous, too, and should include making clients, employees, and shareholders happy. Once in a while it is important, however, to ask for the bottom line, or ultimate objective function, as the discussion on shareholder value has shown. Correspondingly, the ultimate goal of banking supervision should be to make the general public, specifically tax-payers and small depositors, happy.

The cost the general public has to pay in the case of excessive risk taking by banks is primarily associated with the event of bankruptcy. It is incurred through (1) losses by small depositors in the case that deposit insurance is insufficient (e.g. BCCI subsidiary in Hong Kong, 1991) and (2) tax-payers' money to bail out or clean up large institutions or groups of institutions (e.g. Credit Lyonnais, 1994; US Savings and Loans, 1980s).

As discussed by a BIS policy paper (Bank for International Settlements; 1999), "last resort" lending, bail-out of banks using tax-payers' money, as well as deposit insurance should be used in a limited way, as to avoid moral hazard problems. In other words, the failure of banks is an important aspect of a healthy market economy.

In short, the objective of banking supervision should be:

Use the minimal amount of regulation and supervision to prevent fraudulent risk-taking and establish standards of risk disclosure. Minimize the overall cost of banking crises to the general public.

The "New Basel Capital Accord" in its current form seems to be much more concerned with increasing the effectiveness of banking supervision in preventing the failure of individual banks than with decreasing the overall costs to the general public, which include the costs of banking crises and the costs associated with supervision. We show in the next section, that the current quantification of market risk is much more in line with the interests of the shareholders and the management of banks than with the interests of the general public.

\section{Properties and Uses of Value at Risk}

The industry standard for measuring risk is the $99 \%$-quantile ${ }^{2}$ of the distribution of a portfolio's loss over a certain time horizon. This risk measure is explicitly required by the internal-model approach to measuring market risk in the current regulation. It is implicitly used by the "traffic light" penalty and the backtesting. It is also implicitly required as the risk measure to be used at smaller organizational units. In the following, we will use the term quantile$\mathrm{VaR}$ to make explicit that we mean the specific risk measure rather than the

\footnotetext{
${ }^{2}$ A number $q_{\alpha}$ is called $\alpha$-quantile of the random variable $X$ under the probability measure $P$, if $P\left\{X<q_{\alpha}\right\} \leq \alpha \leq P\left\{X \leq q_{\alpha}\right\}$ holds. For a given probability level $\alpha \in(0,1)$, the $\alpha$-quantiles form a closed interval. If $X$ has a probability density that is positive on its domain, then the $\alpha$-quantile $q_{\alpha}$ is uniquely determined by the equation $P\left\{X \leq q_{\alpha}\right\}=\alpha$.
} 
other connotations of Value at Risk. Quantile-VaR is also extensively used in other areas and for other purposes, e.g. for the information of management and shareholders, risk-adjusted performance measurement and compensation, and capital allocation (Jorion; 2000).

On the other hand, there has been an extended discussion on the properties that a risk measure should have in general, and the appropriateness of quantile-VaR as a risk measure specifically (Artzner et al.; 1999). Artzner et al. show, using an example with defaultable bonds, that quantile VaR is not sub-additive, i.e. the desirable property that the risk of an aggregated portfolio is smaller than the sum of the risks of its components is not guaranteed, unless the individual risks are restricted to specific classes of random variables. The conclusion is that

(1) quantile- VaR is an inappropriate risk measure for allocating capital charges - interpreted as trading limits among organizational units of a bank.

The same example can be used to show that quantile-VaR defies common sense diversification. Specifically, the quantile-VaR of undiversified portfolios of defaultable bonds of single debtors can be lower than the quantile-VaR of a corresponding diversified portfolio. ${ }^{3}$

(2) Quantile-VaR is inconsistent with diversification and can thus lead to sub-optimal risk management if used in the context of portfolio optimization or hedging.

Artzner et al. call risk measures coherent, if they have the following four properties that are desirable for regulatory risk measures:

1. sub-additivity $(\rho(X+Y) \leq \rho(X)+\rho(Y))$,

2. positive homogeneity $(\rho(\alpha X)=\alpha \rho(X)$ for positive $\alpha)$,

3. translation invariance $(\rho(X+\alpha \mathbf{1})=\rho(X)-\alpha$ for a numeraire $\mathbf{1}$ and scalars $\alpha$ ),

4. monotonicity $(\rho(X) \leq 0$ for nonnegative random variables $X$.)

Property 2. makes sense for regulatory risk measures, since banks would otherwise have an incentive to split up large portfolios into identical small ones and transfer them to artificial legal units. Sub-additivity and convexity are equivalent under 2 . Property 3 . ensures that $\rho$ can be interpreted as measuring "how much value is at risk?".

\footnotetext{
${ }^{3}$ Mathematically speaking, quantile-VaR is not convex$$
\rho(\lambda X+(1-\lambda) Y) \leq \lambda \rho(X)+(1-\lambda) \rho(Y) \quad(\lambda \in[0,1])
$$

on a large enough set of risks. 
While the lack of sub-additivity and convexity of quantile-VaR is inconvenient, it is not a significant argument to reject quantile-VaR as a measure for determining the capital requirements at a firm-wide level. A more stringent reason to use a different measure to determine capital adequacy is the ultimate objective of banking supervision. Quantile-VaR can be interpreted as the minimal loss in the 1\% "bad" cases. It does not say anything about the expected loss in the "bad" cases. Depositors, contributors to deposit insurance, creditors, and potentially tax-payers are those that have to bear the loss that exceeds the remaining capital in the case of bankruptcy. Banking supervision should try to minimize the expected loss in the event of bankruptcy. The appropriate way to quantify the minimal required capital is thus expected shortfall (or mean excess loss)

$$
\operatorname{ES}_{\alpha}(X)=\mathrm{E}\left[-X-\operatorname{VaR}_{\alpha}(X) \mid-X \geq \operatorname{VaR}_{\alpha}(X)\right]
$$

for some appropriate confidence level $\alpha$ and tail conditional expectation (or TailVaR, conditional VaR, beyond VaR)

$$
\operatorname{TCE}_{\alpha}(X)=\mathrm{E}\left[-X \mid-X \geq \operatorname{VaR}_{\alpha}(X)\right],
$$

where $\mathrm{TCE}=\mathrm{VaR}+\mathrm{ES}$ has the properties of a risk measure.

(3) Quantile-VaR is inappropriate for the measurement of capital adequacy, as it controls only the probability of default, but not the average loss in the case of default.

Quantile-VaR is "blind" towards risks that create large losses with a very small probability (below the critical probability level $1-\alpha$ ). If quantile-VaR is used for risk-adjusted compensation or as a trading limit, then traders have an incentive to run strategies that exactly generate such risks. There are several possibilities to generate almost sure profits with a small probability of large losses, e.g.

- Increase the bet until a certain profit is reached. (The classical doubling strategy.)

- Buy defaultable bonds and sell risk-less bonds (LTCM).

- Sell far-out-of-the-money put options.

- Sell insurances (financial derivatives) for rare events.

While other trading limits than VaR-limits will somewhat restrict a trader's ability to run these strategies in practice, many possibilities remain, as nicely documented by Taleb (2000), who calls strategies of this kind "Peso problem strategies". 
(4) Quantile-VaR is the wrong risk measure to use as a trading limit or in the context of risk-adjusted compensation. Used in this way, quantile-VaR creates incentives for traders to run exactly those strategies that have been the cause for some spectacular losses in the past.

This is true at all levels of aggregation, also at the firm level, which leads to the next point:

(5) Quantile-VaR is the perfect risk measure from the viewpoint of shareholders and management.

Shareholders' costs associated with bankruptcies - legal costs, loss of goodwill, etc. - are almost independent of the size of the loss that triggers the default. The same is true for the costs borne by management, which are also primarily related to the default event itself. Both shareholders and management are interested to minimize the probability of default. In other words, they want to minimize the cost of a digital put option on the firm's value. In a risk-neutral world

$$
\operatorname{VaR}_{\alpha}(X)=-\sup \left\{q \mid \mathrm{E}\left[\mathbf{1}_{\{X \leq q\}}\right] \leq 1-\alpha\right\}
$$

would be "(minus) the lowest strike price of a digital put option on $X$, such that its price is at most $1-\alpha . "$ The expected shortfall

$$
\mathrm{ES}_{\alpha}(X)=\frac{1}{1-\alpha} \mathrm{E}\left[\left(X-\operatorname{VaR}_{\alpha}(X)\right)^{-}\right]
$$

could be interpreted as the price of a "(European) put option with a strike at the VaR level, divided by the price of the corresponding digital put option."

Hence

(6) there is a conflict of interest on the choice of the proper risk measure between shareholders and management on the one hand and depositors, creditors, and tax payers on the other hand.

While the former should prefer quantile-VaR as a risk measure and digital put options on the firm as hedge instruments, the latter should prefer TCE as a risk measure and (classical) put options on the firm as hedge instruments. More pointedly, the current regulation uses lots of resources - funded by taxpayers and banks' customers - to enhance the risk management of banks. But this is done in a way that the banks' shareholders and management are the primary beneficiaries and tax-payers and depositors benefit only disproportionately. The proposed new regulation intends to significantly increase the cost of supervision in the same inappropriate way. This and the fact that the extensive discussions about the short-comings of quantile-VaR apparently 
have had no effect on the proposed "New Accord" is highly unsatisfactory from a normative point of view.

On the positive side, the risk measures implicitly defined by the internal ratings based approach to credit risk and organizational risk resemble TCE more than they resemble VaR, as they depend on the "loss given default/event" instead of only the probability of default/event. It is to be hoped that the way the risk measures are calibrated in the final version is more aligned with the interests of the general public than with the interests of banks' shareholders.

\section{The Relation between Quantile-VaR and TCE}

The above discussion would be completely irrelevant if there would be a strong relation between Quantile-VaR and TCE. This is in fact the case for specific classes of loss distributions. If the loss has an exponential distribution, i.e. the change in the portfolio value has a probability density $f(x)=\lambda e^{-\lambda|x|}$ on the interval $(-\infty, 0)$ for some decay rate $\lambda>0$, simple computations show that

$$
\mathrm{TCE}_{\alpha}=\frac{1}{\lambda}+\mathrm{VaR}_{\alpha}
$$

holds. In other words, TCE is just a bit larger than VaR and this can be adjusted for by adding the inverse of the decay rate. If the loss has a power tail, i.e. the change in the portfolio value has a probability density $f(x)=\beta|x|^{-\beta-1}$ on the interval $(-\infty,-1)$ for same tail parameter $\beta>1$, simple computations show that there is a constant ratio between TCE and VaR:

$$
\mathrm{TCE}_{\alpha}=\frac{\beta}{\beta-1} \mathrm{VaR}_{\alpha} .
$$

This means that even in the case with the fattest possible tails - within the confines of parametric approaches to modeling the tail - the deficiencies of quantile-VaR criticized in the previous section can simply be adjusted for by multiplication with an appropriate factor. This adjustment would be conservative for large enough portfolios in the case of less heavy tails, i.e. exponential or Gaussian tails.

However, any level of TCE can be reached by "Peso problem strategies" with restricted VaR:

$$
\mathrm{P} \& \mathrm{~L}=\left\{\begin{array}{rr}
1+2 p(x-1) & \text { with probability } \\
-1 & 0.5 \\
-x & 0.5-p \\
& p
\end{array}\right.
$$

with $p<1-\alpha<0.5$ and $x>1$. Letting $x$ tend to $\infty$, the VaR is constant $\left(\operatorname{VaR}_{\alpha}=1\right)$, but the TCE is unbounded $\left(\mathrm{TCE}_{\alpha}=1+2 p(x-1)\right)$. If this example sounds too artificial, we may refer again to (Taleb; 2000) or the LTCM strategy (Jorion; 2000, section 21.4) for real-world "Peso problem strategies". 
Conclusion is that in cases where the tail of a loss distribution can be modeled well by the generalized Pareto distributions suggested by extreme value theory (Embrechts et al.; 1997), the choice of VaR over TCE as a risk measure is cosmetic. This will usually be the case if the loss distribution is determined somewhat exogenously (operational risk), or comes from many independent sources (large aggregates of portfolios). The real challenge of risk controllers is, however, to identify and prevent traders from running "Peso problem strategies". ${ }^{4}$ This requires non-parametric modeling techniques.

\section{Conclusion}

Starting from the objective of banking supervision - to minimize the overall costs of banking to the general public - we showed that the current standard of quantifying market risk is flawed. It is perfectly aligned with the interests of banks' shareholders and management, but not with the interests of the general public.

The Basel Committee continually repeats that the proposal for the "New Accord" is the result of "extensive discussions", "ongoing dialogue", and "ongoing consultation" with the industry. There is no doubt that this is absolutely necessary to get the details of the "Accord" right. Dialogue with the industry, however, is no substitute for consultation with tax payers' organizations, who should be considered the most important "interested party". Paraphrasing Covey, the "New Accord" does some significant steps up the ladder of risk management, but currently the ladder is leaning against the wrong wall.

\section{References}

Artzner, P., Delbaen, F., Eber, J.-M. and Heath, D. (1999). Coherent measures of risk, MF 9(3): 203-228.

Bank for International Settlements (ed.) (1999). Bank Restructuring in Practice, number 6 in BIS Policy Papers, BIS, Basel. http://www.bis.org/ publ/plcy06.pdf.

Basel Committee on Banking Supervision (2001). The New Basel Capital Accord, http://www.bis.org/publ/bcbsca.htm.

Covey, S. R. (1990). The 7 Habits of Highly Effective People, Franklin Covey.

Embrechts, P., Klüppelberg, C. and Mikosch, T. (1997). Modelling extremal events, Springer-Verlag, Berlin.

\footnotetext{
${ }^{4}$ Note that we believe that many institutions already have incentives and limits in place that prevent many Peso problem strategies. But this is not because of banking regulation (based on quantile-VaR), but despite of it.
} 
Jorion, P. (2000). Value at Risk: The New Benchmark for Managing Financial Risk, McGraw-Hill, New York.

Taleb, N. (2000). Fooled by randomness: If you're so rich why aren't you so smart?, http://pw1.netcom.com/ ${ }^{\sim}$ taleb/trader.htm. unfinished book, some sections online. 